\title{
الحماية الجنائية للمستهلك من الإثهارات الكاذبة
}

\section{د. عيساوي زاهية \\ كلية الحقوق،والعظوم السياسية \\ جامعة مولود معمري تيزي وزور المبية}

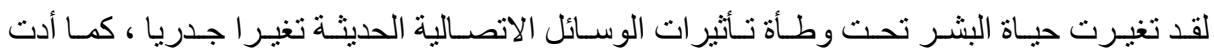

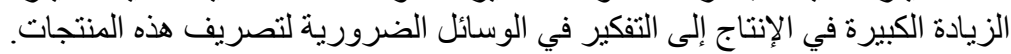

بغية تقريب المنتجات من المستهلاك وتر غيبه في استهلاكها و اقتتائها، ظهر ما يسمى بالإشهار التجاري

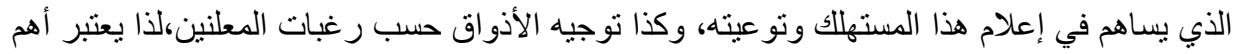

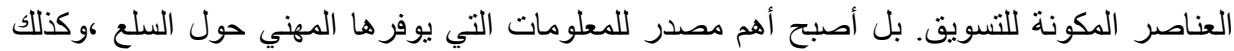

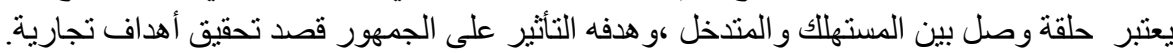
تتم هذه العلمية في محيط تسوده الحرية مما يصبغها بأساليب الإثارة و التركيز على الغرائز والخروج

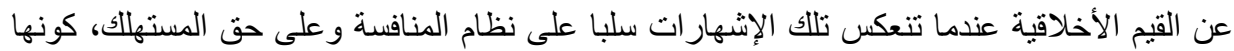

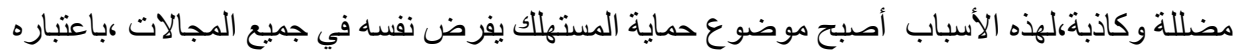

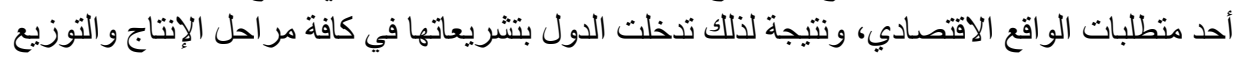

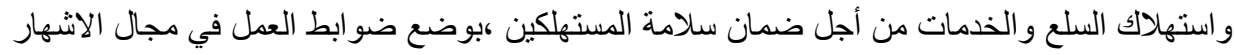

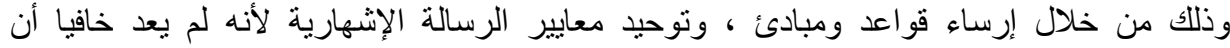

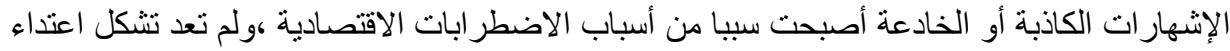

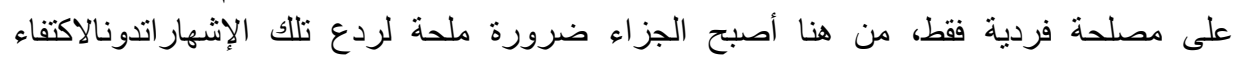

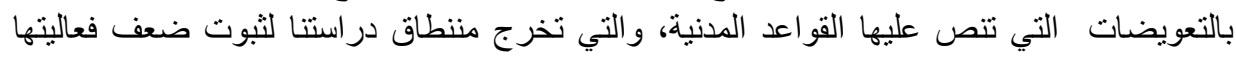

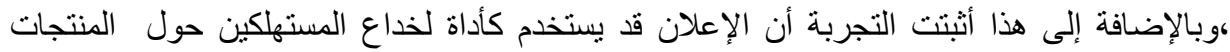

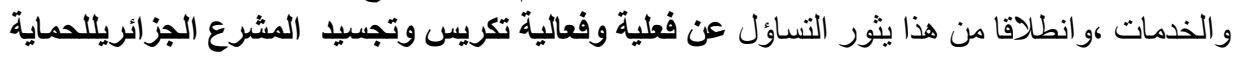
الجزائية للمستهلك من الاشهارات التجارية الكاذبة ؟

والإجابة على هذه الإثكالية تكون ضمن محورين، حيث سنتناول في الأول الحماية الموضوعية

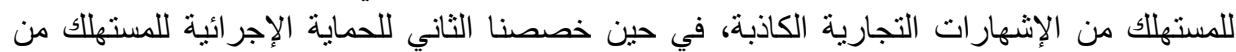

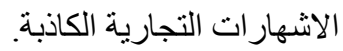

المحور الأول: الحماية الموضوعية للمستهلك من الاثهارات التجارية الكاذبة.

باستقراء نصوص قوانين حماية المستهلك بستثف أن المشرع الجزائري قد حدد أحكامموضوعية

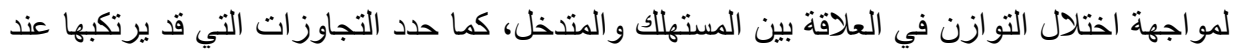

(C) جامعة الإخوة منتوري قسنطينة، الجزائر 2015 


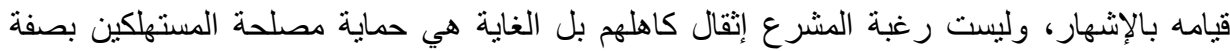

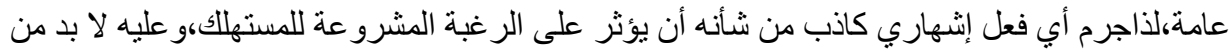

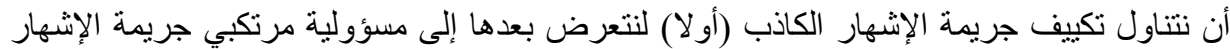
الكاذب مع تحديد العقوبات المقررة لهم (ثانيا). أولا:تكييف جريمة الإشهار الكاذب:

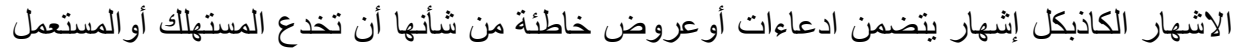

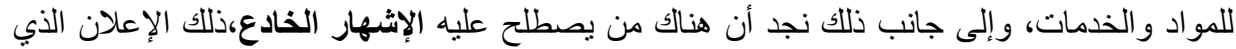

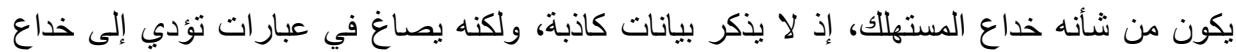

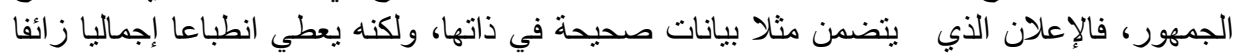

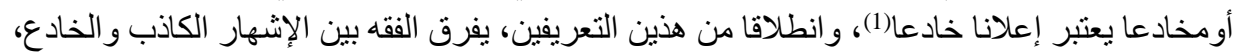

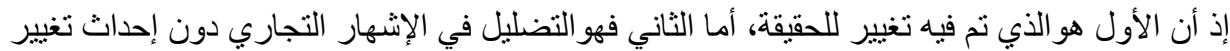

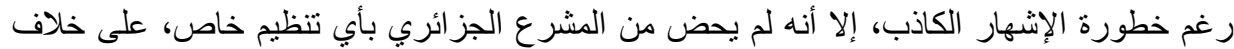

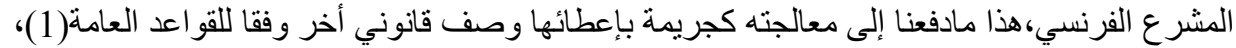

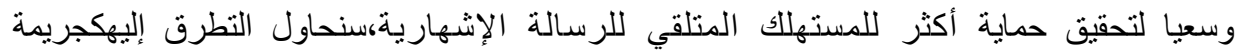

مستقلة قائمة بذاتها(2).

\section{1- إعطاء الإشهار الكاذب تكييف قانوني أخر:}

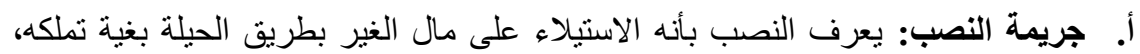

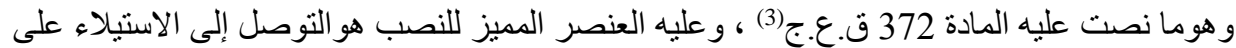

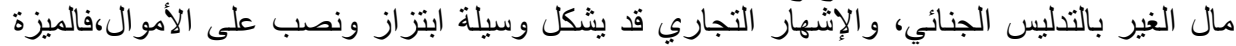

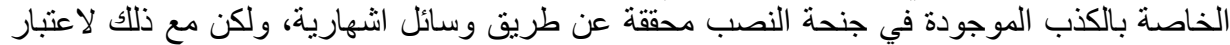

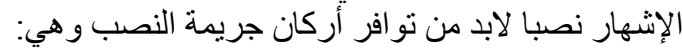
- الركن المادي: يتحقق هذا الركن عن طريق استعمال وسيلة من وسائل التدليس ويتكون من

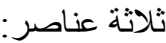

• استخدام طرق احتيالية:قد يصل الكذب إلى درجة الطرق الاحتيالية إذا اقترن بأعمال مادية

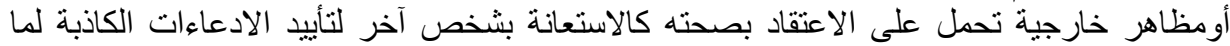

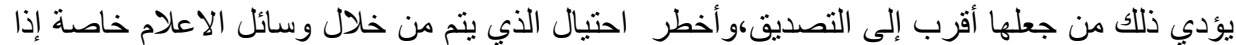

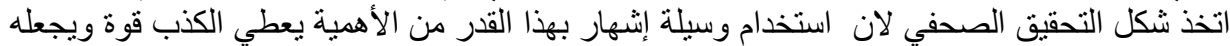

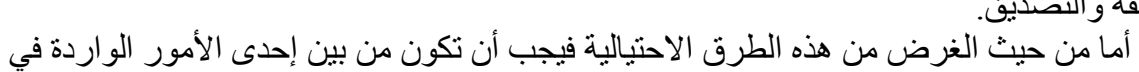

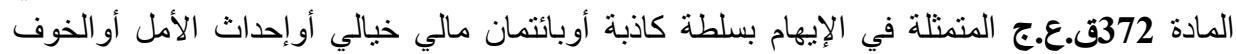

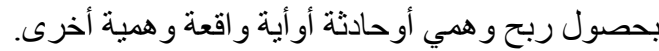

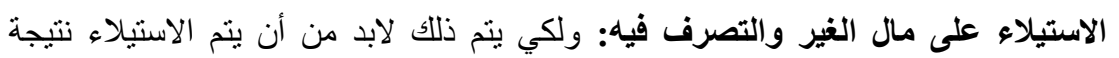

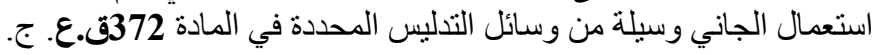


علاقة السبيية بين الوسائل الاحتيالية والاستيلاء على مال الغير: بمعنى أن يكون ذلأك

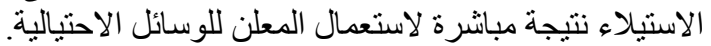

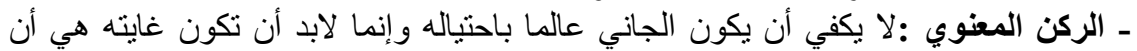

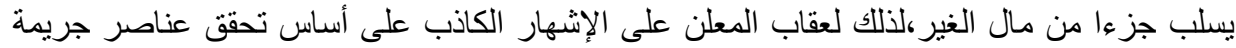

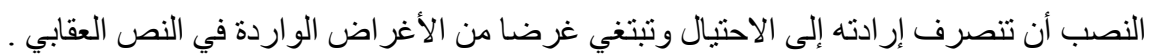

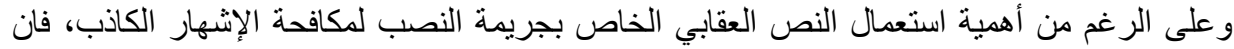

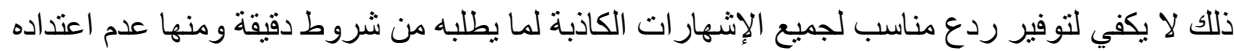

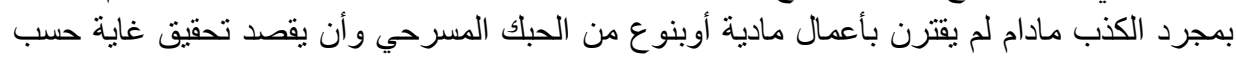

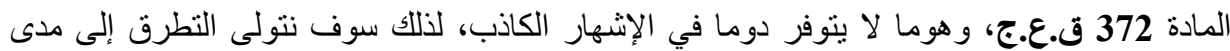
إمكانية إعطاء وصف جريمة الخداع على لأن الإشهار.

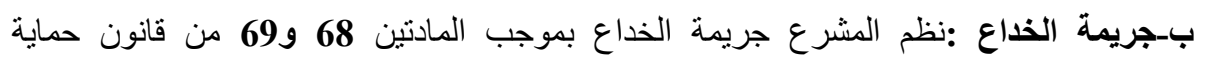

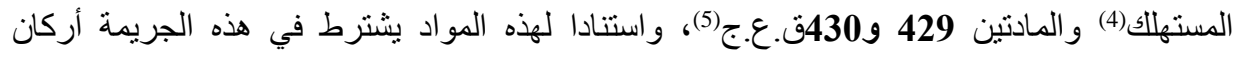
لقيامها:

ـ الركن المادي: يجسد النشاط المادي للخداع، في كل فعل أو نشاط يصدر عن الجاني، يهذف من ورائه

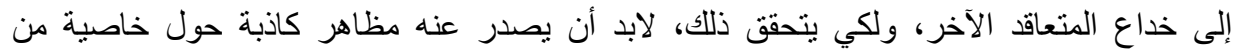

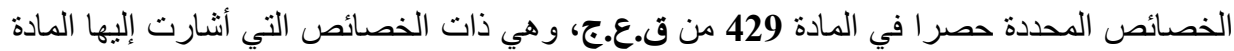

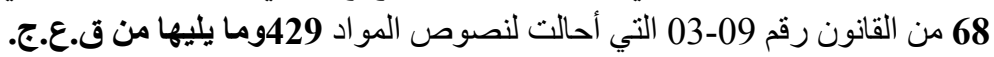

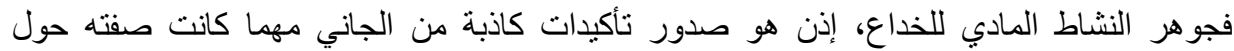

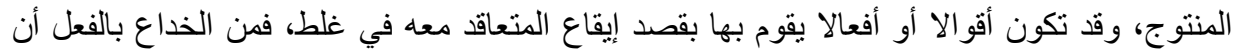

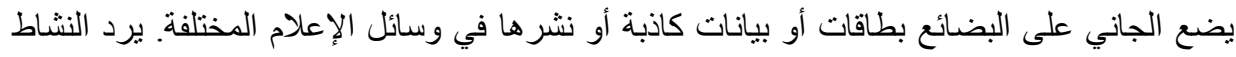

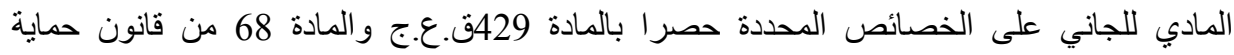

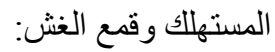

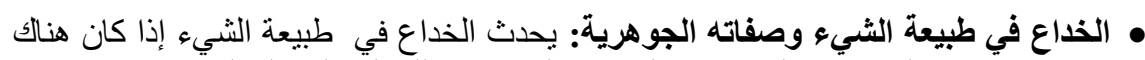

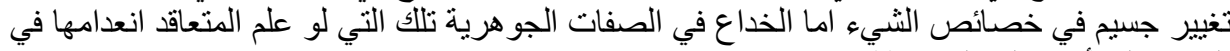

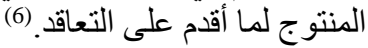

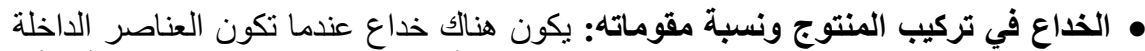

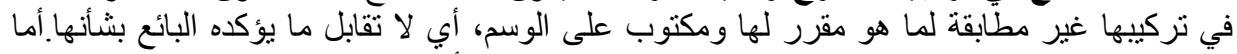

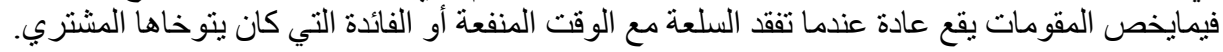

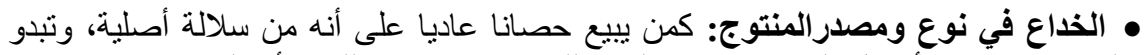

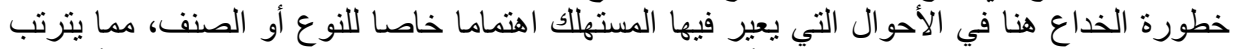

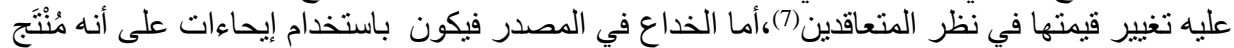

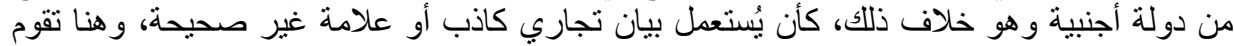

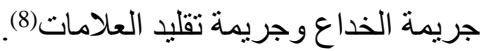
• الخداع في كمية وهوية المنتوج:يكون إذا كان ما سلم منها للمتعاقد غير ما تم الاتفاق عليه. 
و عموما فإن ما يمكن قوله بشأن هذه الخصائص أنها متداخلة فيما بينها إلى درجة يصعب معها أحيانا

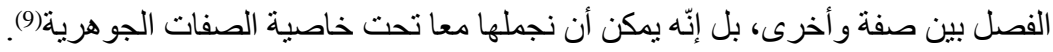

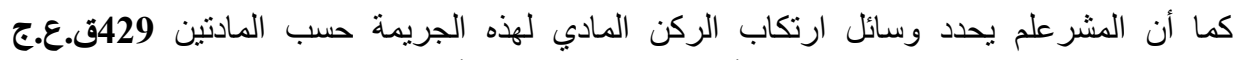
و المادة68من قانون 03-09، مما يكون بأي وسيلة كانت، المهم أن تؤدي إلى إيقاع المستهلك في الغلط الئل

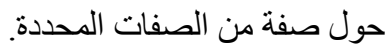

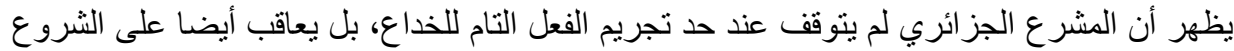

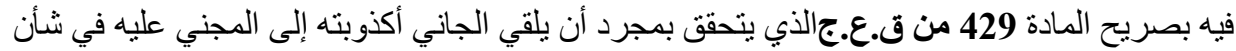

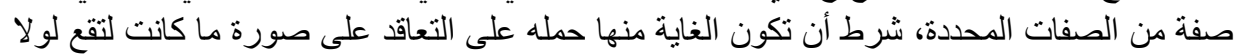

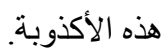

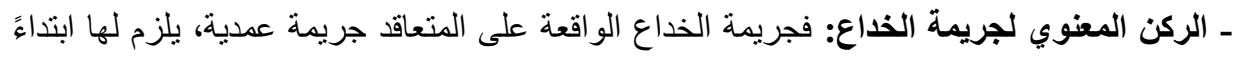

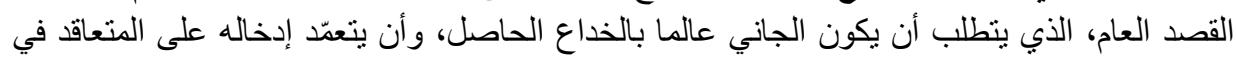

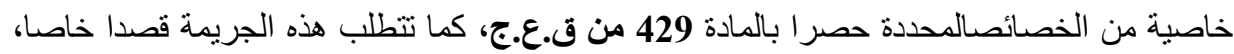
هو نية التعامل في السلعة والتعاقد عليها بعوض. بالكان.

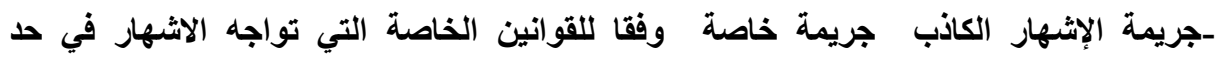

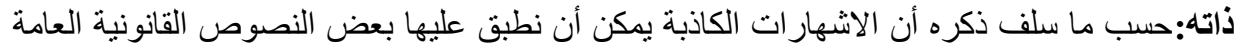

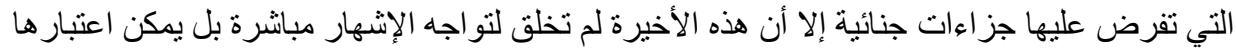

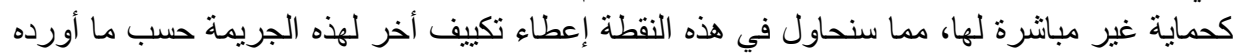

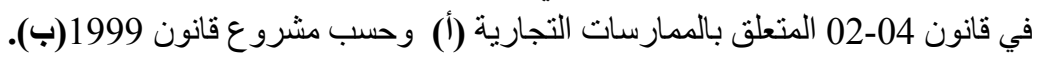

أـ الإثهار الكاذب وفقا للقانون المتعلق بتحديد القواعد المطبقة على الممارسات

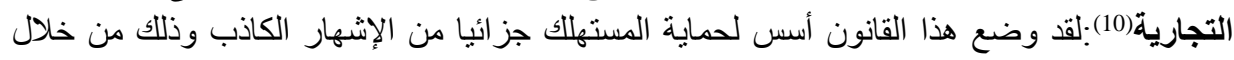

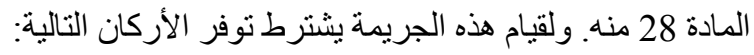

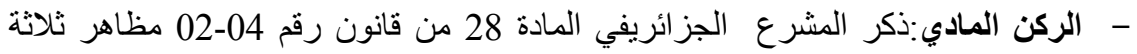
للسلوك الذي يكون إنشهار اكاذبا أو تضليليا.

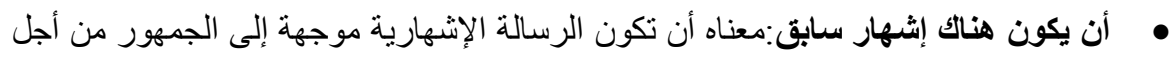

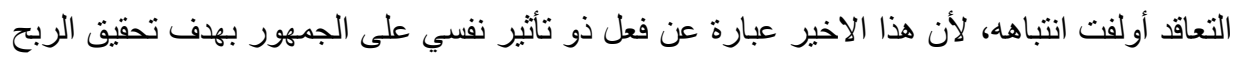

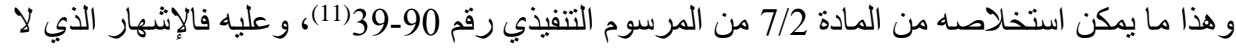

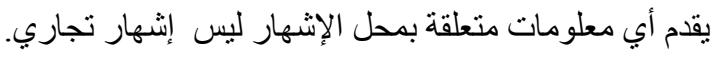

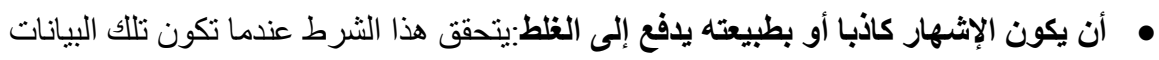

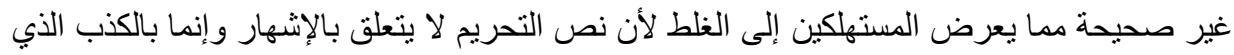

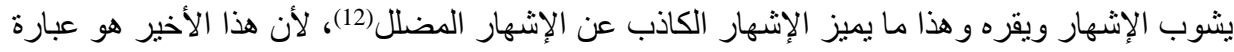

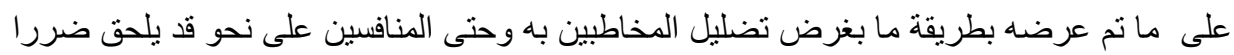

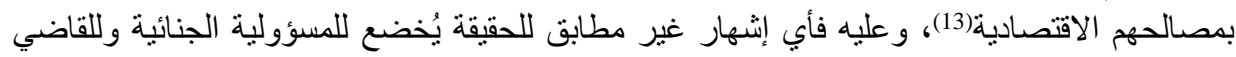

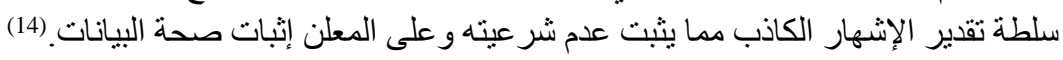




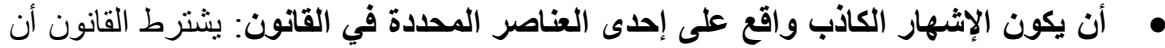

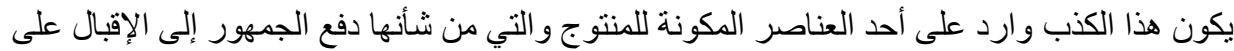

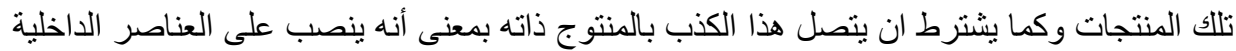

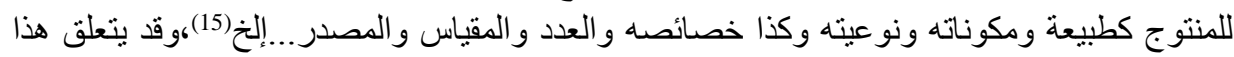

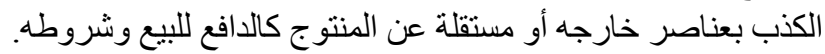

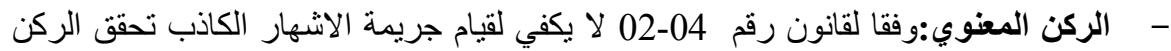

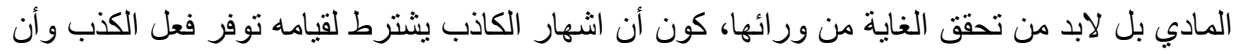

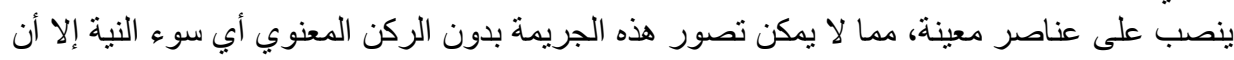

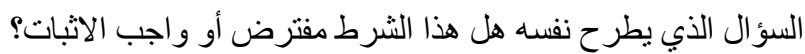
يمكن القول أن الثرط المعنوي هو شرط مفترض يقع على عاتق العون الاقتصادي إثبات حسن نيته.

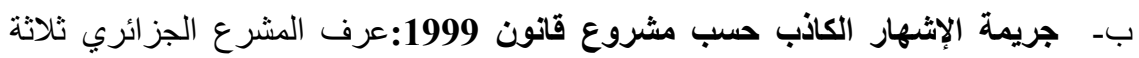

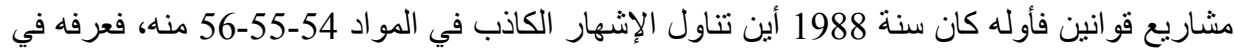

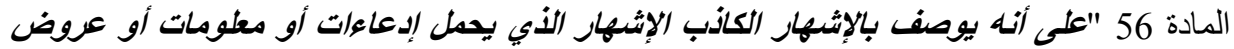

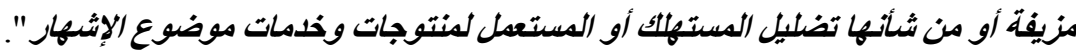

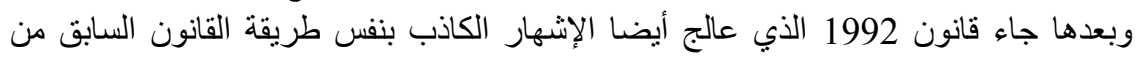

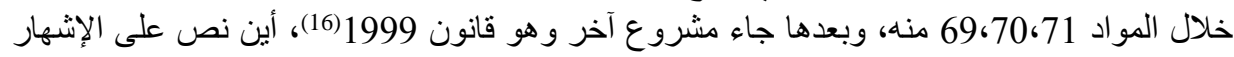

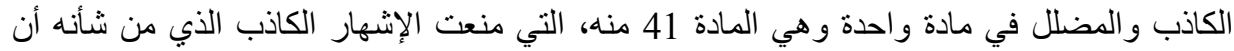

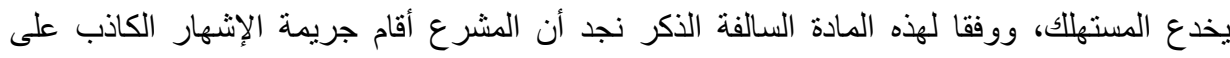

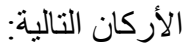

ـالركن المادي: و الذي يتحقق عند بث رسالة إثهارية تتضمن ادعاءات أو عروض خاطئة من

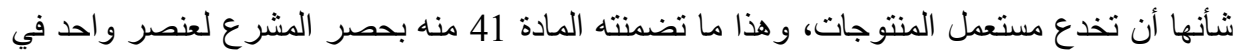

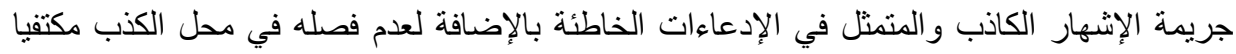

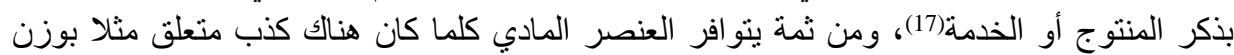

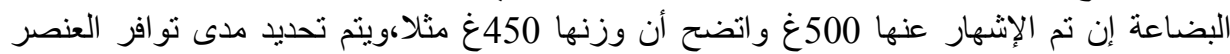

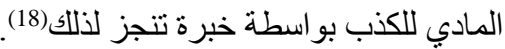

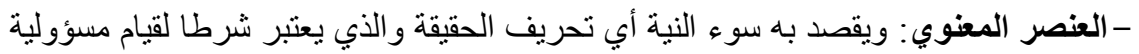

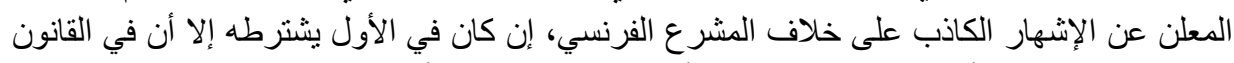

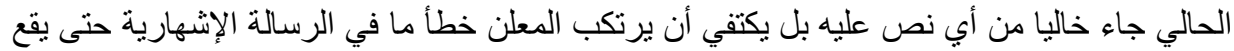

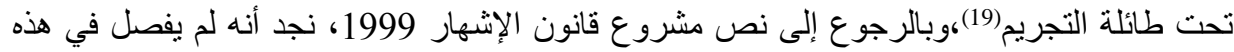

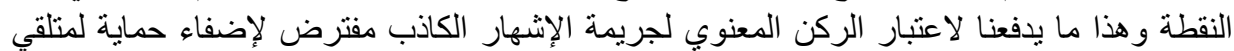

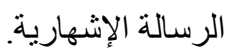
ثثانيا: تحديد المسؤولة جزائيا عن الاشهارات التجارية الكاذبة والعقوبات المقررة.

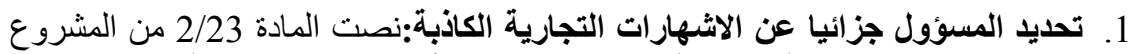

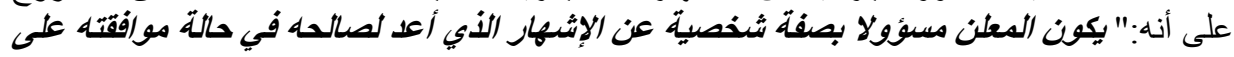


النص قبل بثه أو نشره "،ويعد معلنا أيضا كل شخص طبيعي أو معنوي يدرج إعلانا الشهاريا أو يوكل

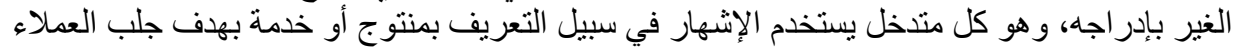

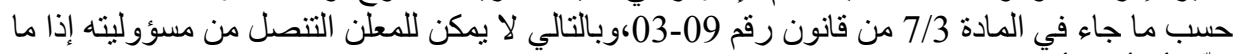

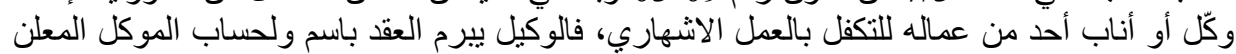

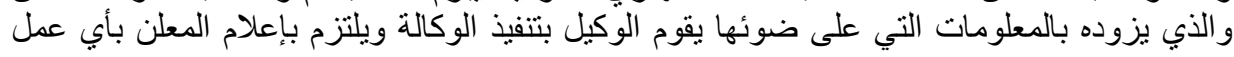

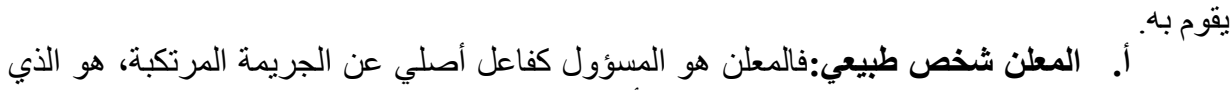

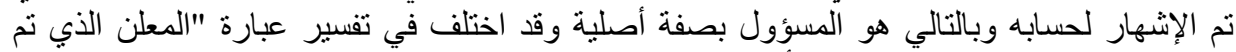

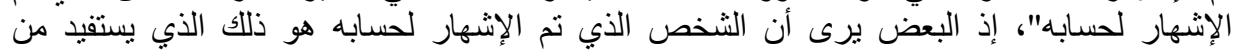

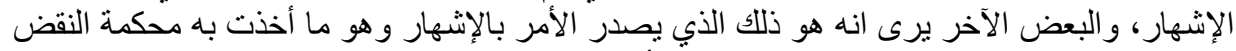

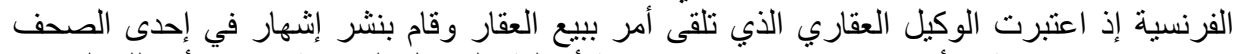

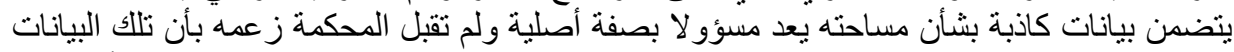

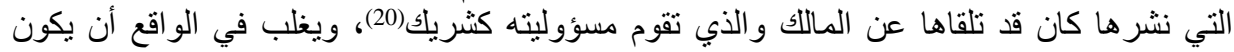

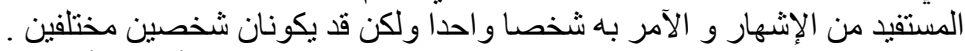

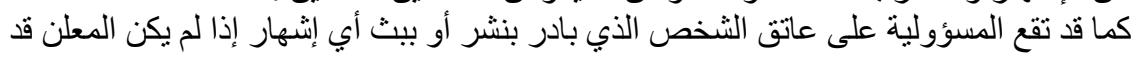

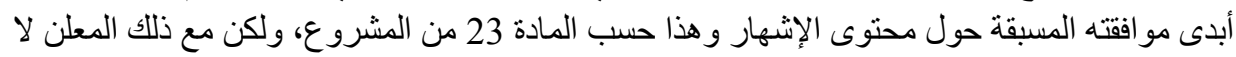

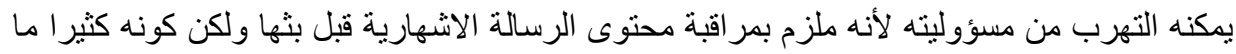

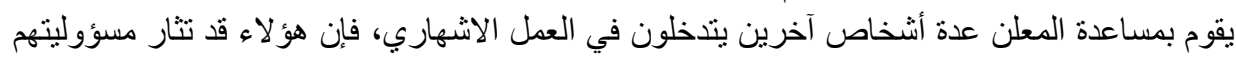

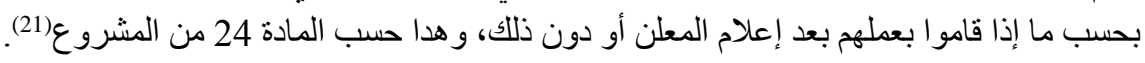

ب. المعلن شخص معنوي:إذ أن الأصل المعلن هو الذي يقوم بإعداد وبث الرسالة الاشهارية

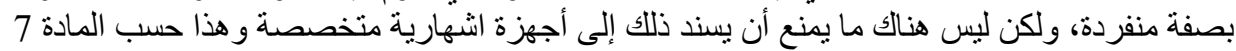

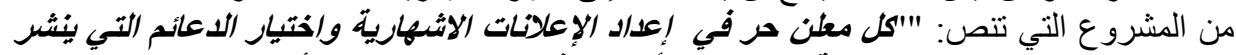

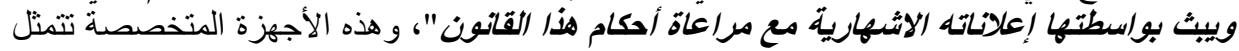

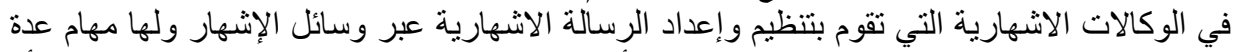

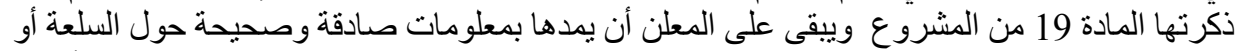

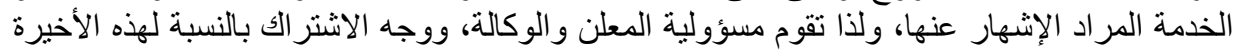

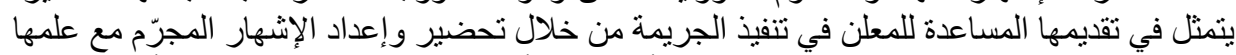

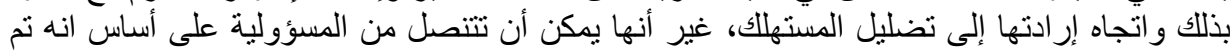

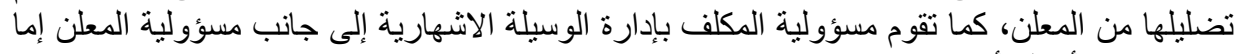
بصفته فاعلا أصليا أو شريكا.

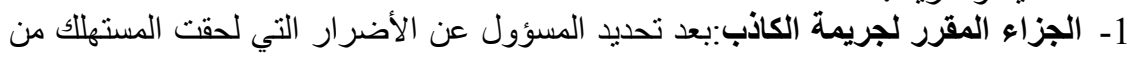

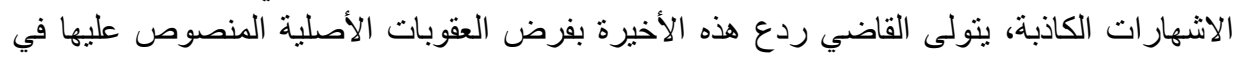

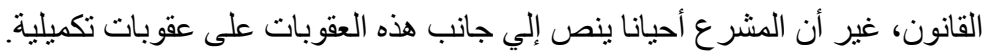

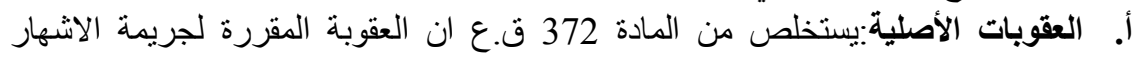

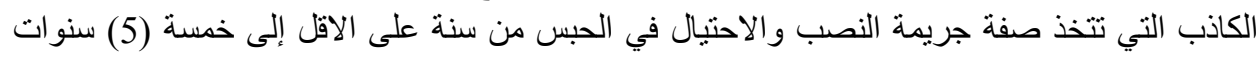

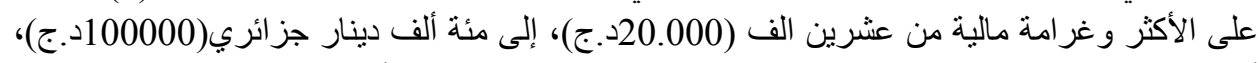

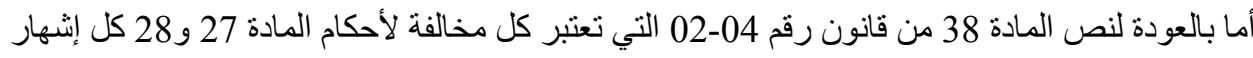

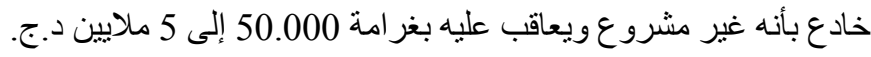




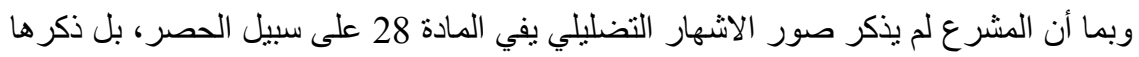

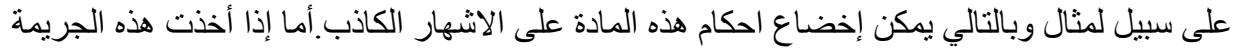

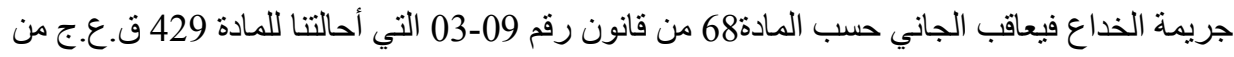

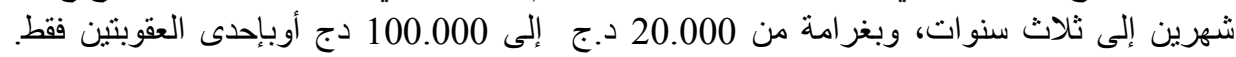

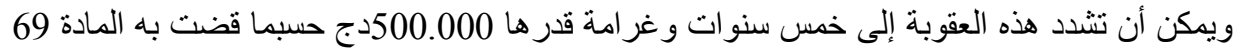

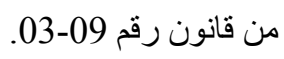

وفي ظل توسع نثاط الأثخاص المعنوية أقر المشرع الجز ائري فقد أقر بالمسؤولية الجزائية للثخص

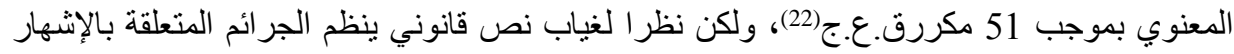

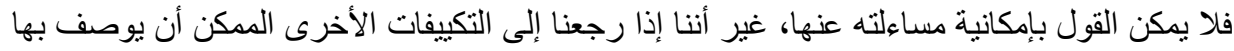

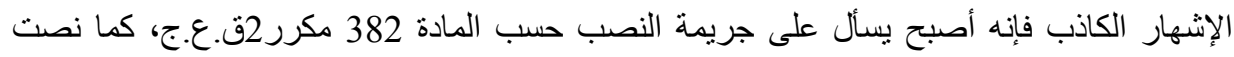

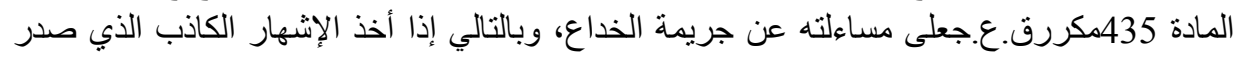

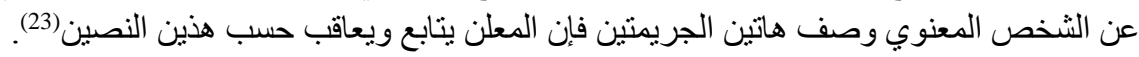

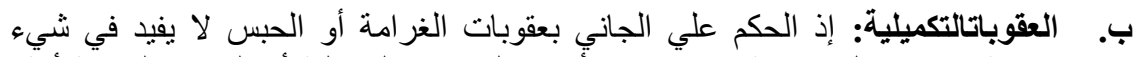

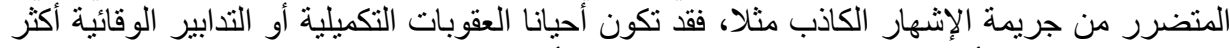

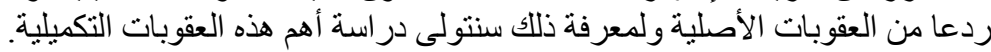

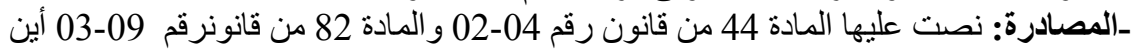
أجازت للقاضي مصادرة السلعة المحجوزة في حالة ارتكاب المخالفة المتعلقة بالإشهار .

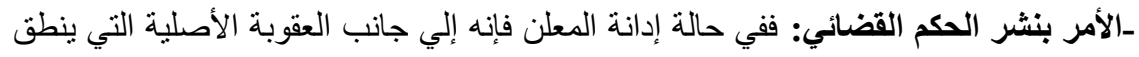

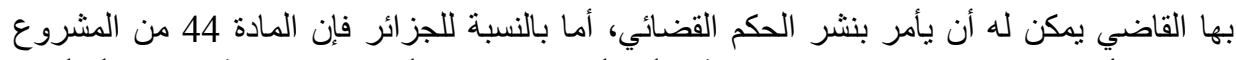

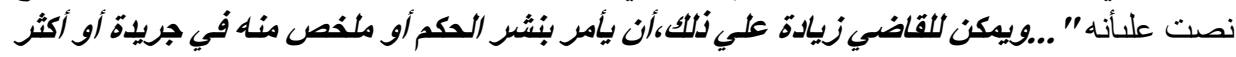

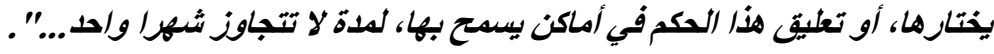

فبذلك تكون هذه المادة قد جعلت الأمر بنشر الحكم إجراء جوازي، وبالتالي إصداره يخضع للسلطة

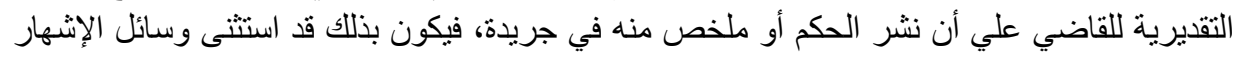

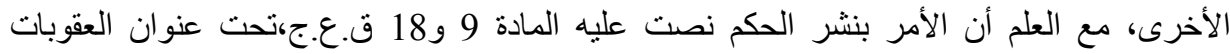

ـالحكم بنشر أو ببث الاشهارالتصحيحي: تعثبر عقوبة تكميلية جوازيه استحدثها القانون الفرنسي لسنة

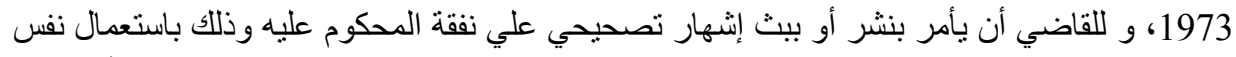

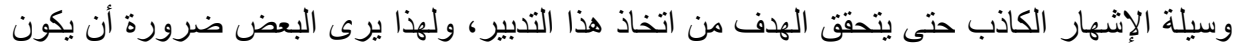

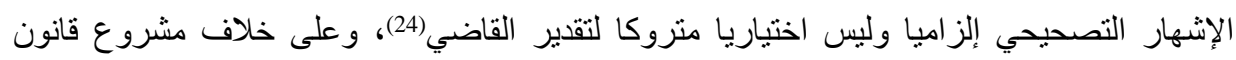

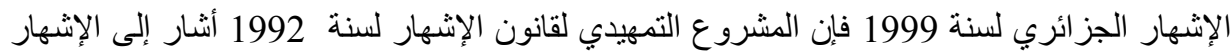

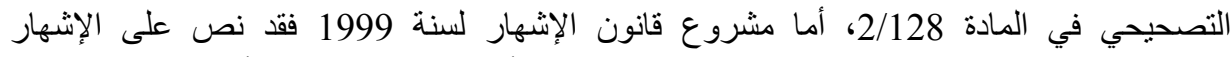
التصحيحي في المادة 2/38في ظل العمل التحضيري، غير أنها حذفت بعد تقايمه أمام المجلس الثعبي الأنهار 
المحور الثاني: الحماية الإجرائية للمستهلك من الإثهارات التجارية الكاذبة:

بعد أن بينتا مختلف الأفعال الإشهارية التي جرمها المشرع قصد حماية المستهلك الذي يعد

طرفا ضعيفا تأتي في هذا الدحور الثاني لتبيان الأحكام الإجرائية التي من شأنها أن توفر حماية لهمن التهن

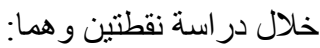

$$
\text { - كيفية معاينة جريمة الإشهار الكاذب ( أولا). }
$$

أولا: معاينة جريمة الإثهار الكاذب:

بالرجوع إلى المو اد 49 إلى 59 من قانون رقم 04-02 حددت الموظفون المؤهلون بالقيام بهذه المعاينة مع تحديد اختصاصاتهم في ذلك الكي:

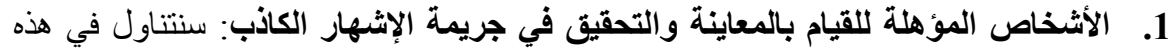
النقطة مختلف الأشخاص المؤهلة قانوننا بإجراء هذه المعاينة من أجل الكثنف عن جريمة الاشهار

أـــضباط الثرطة القضائية وأعوان الضبطية القضائية: ذكر المشرع الجزائري على سبيل

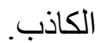

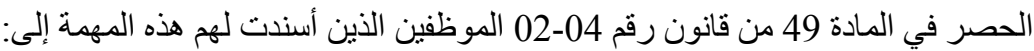

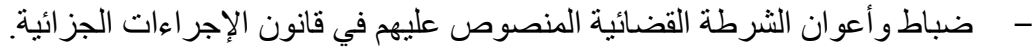

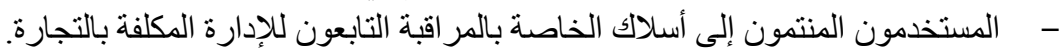

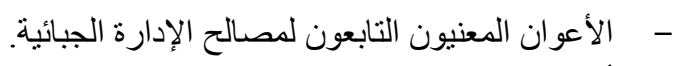

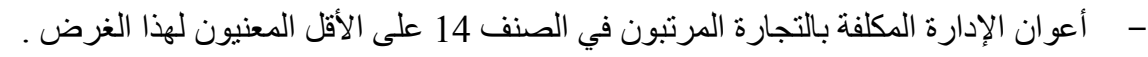

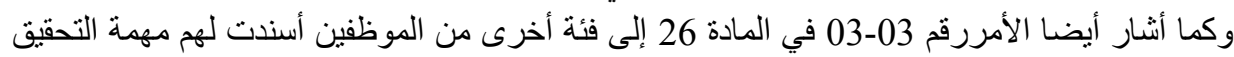

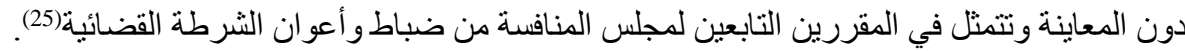

بـ المستخدمون المنتمون إلى الأسلاك الخاصة بالمراقبة التابعون للإدارة المكلفة بالتجارة والأعوان التابعون لمصالح الإدارة الجبائية:

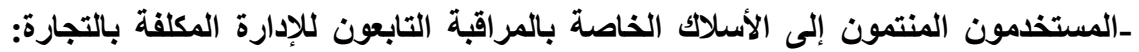

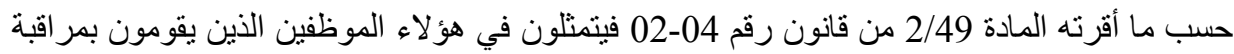

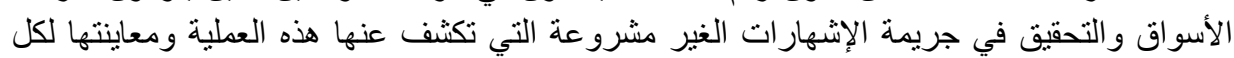

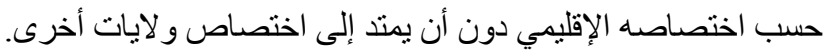

ـالأعوان التابعون لمصالح الإدارة الجبائية:يتم تعيين من بينهم أعوان تسند إليهم مهمة المعاينة و التحقيق في جميع المخالفات بما فيها جريمة الإعلان الكاذب.

و هذه الفئة تم إدراجها مؤخر ا في قانون رقم 04-02 بهدف توفير أليات من شأنها أن تسهر على ضبط

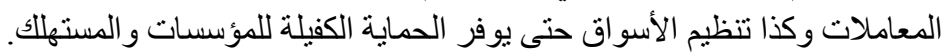




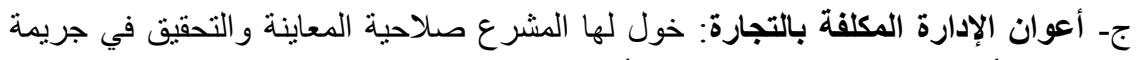

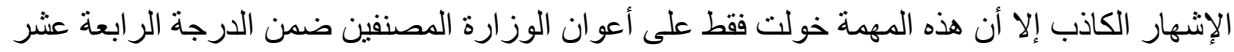
على أقل تقدير.

\section{1- اختصاصات الموظفين المؤهلين للقيام بالمعاينة والتحقيق في جريمة الإشهارات}

حصر المشر ع الجز ائري المهام المخولة للموظفين القائمين بالتحقيقات الاقتصادية في وظيفتين أساسيتين

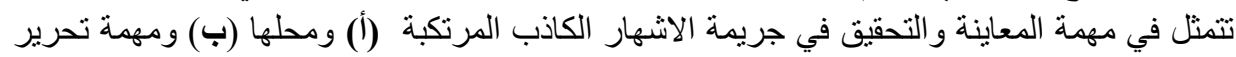
المحاضر من جهة اخرى (ج).

أــ المعاينة والتحقيق:من خلال هذه المرحلة يمكن جمع الأدلة والقرائن المختلفة والتي تؤكد

$$
\text { وقوع الجريمة أم لا. المانة }
$$

وباستقر ائنا لنص المادتين 50 و 52 من قانون رقم

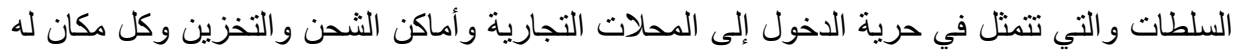

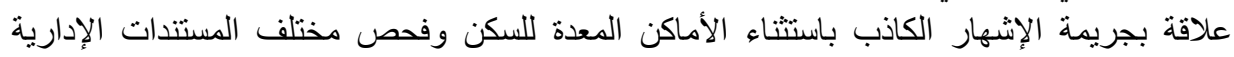
و المالية و المحاسبية...إلخ.

وكما يجوز لهم حجز تلك المستندات وإضافتها إلى المحضر حتى تكون بمثابة إثبات ضد المؤسسة المخالفة أو إعادتها عند نهاية التحقيق.

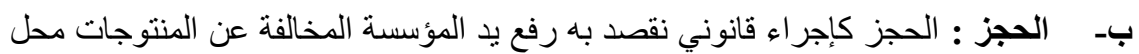

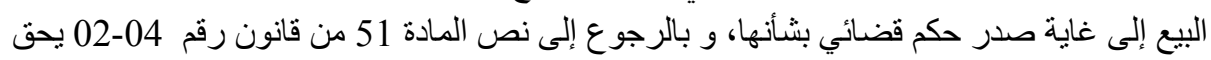

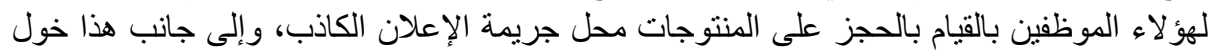

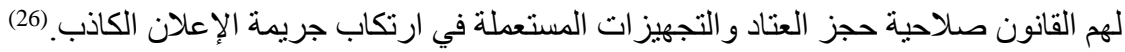

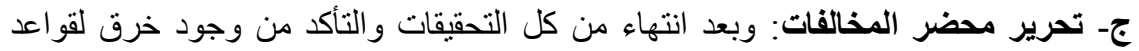
الموظفين تثبت جريمة الإعلان الكاذب في محضر يقوم بتحريره الموظفون المؤهلون بالمعاينة

ويحرر هذا المحضر في ظرف 8 أيام تبدأ من تاريخ نهاية التحقيق تبين فيه هوية الموظفين الذين

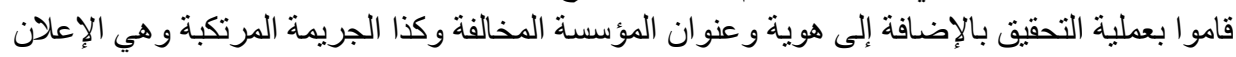

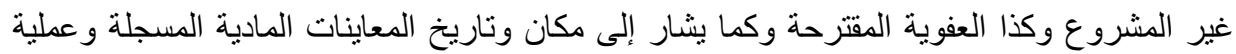
الحجز في حالة حدوثها. وكما ينبغي أن يذكر في الحضر الى أن مرتكب جريمة الإعلان الكاذب تم إعلامه بمكان وتاريخ تحرير المحضر وبضرورة الحضور ، أما إذا غاب أو رفض الكض الحضور للتوقيع يثبت ذللك في المحضر. ولكي يكون هذا المحضر صحيحا يجب أن ينم إمضائه من طرف الموظفين الذين عاينوا شخصيا

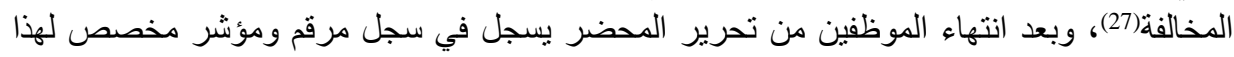


الغرض،وييلغ إلى المدير الو لائي المكلف بالتجارة الذي وقعت المعاينة في دائرة اختصاصه وبمجرد ارسال الملف الى الجهة المختصة تنتهي بذللك مهمة الموظفين المكلفين بالمعاينة والتحقيق,

ثانيا: متابعة جريمة الإشهار الكاذب كوسيلة لحماية المستهلك.

من خلال القانون رقم 02-04 المتعلق بالممارسات التجارية نجد أن المشرع الجزائري أقر حماية

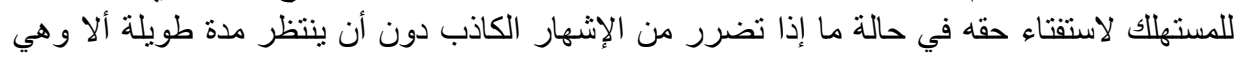

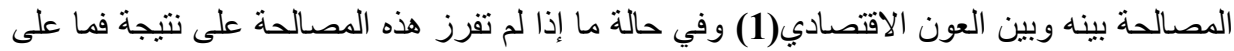
المتضرر و إلا اللجوء إلى القضاء(2).

1- المصالحة:حدد المشرع نطاق المصالحة والصلح بنصوص القانون فنطبيقا لقانون رقم

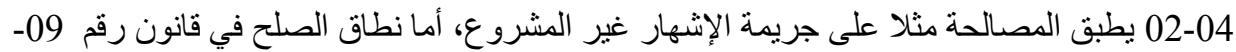

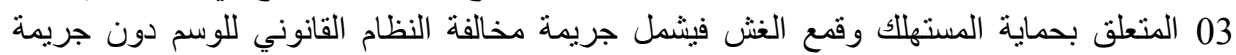

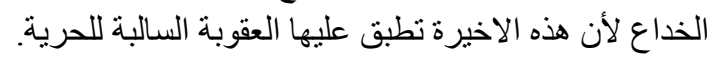
ولذا سندرسها في إطار قانون رقم

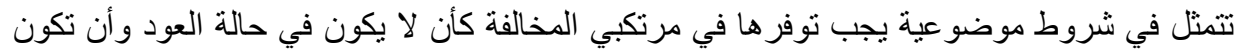

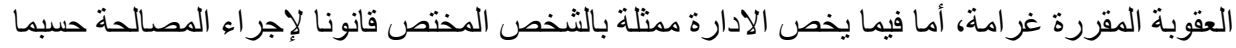

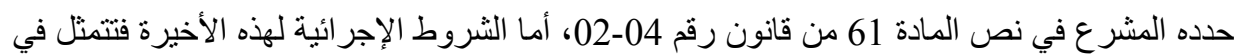

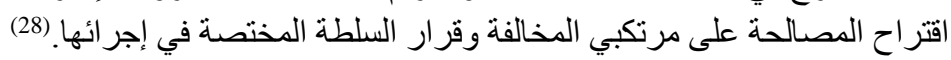

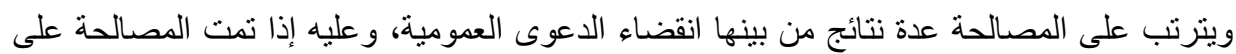

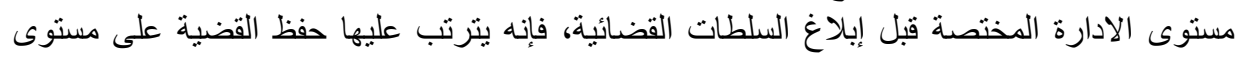

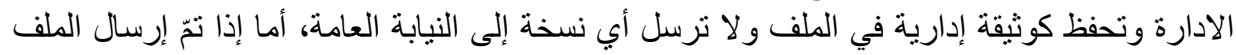

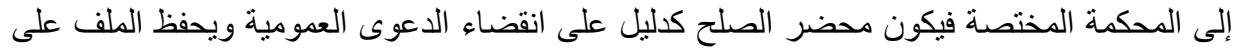

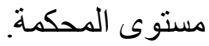

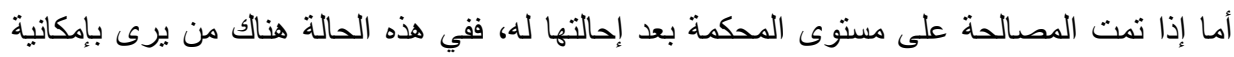

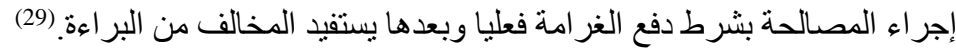

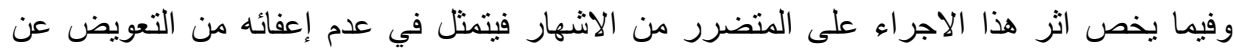
الضرر الذي لحقه جراء الاشهار الكاذب مما يمكن له رفع داء دعوى مدنية لاستيفاء أو إبطال العقد أو أون

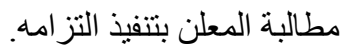

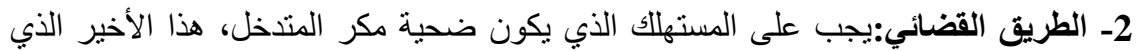

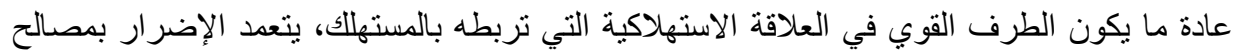

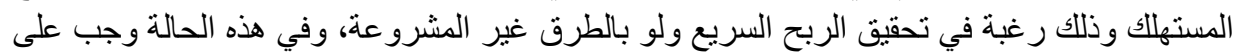

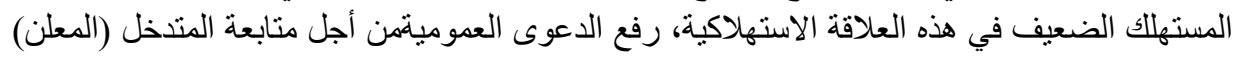

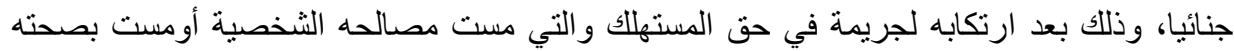




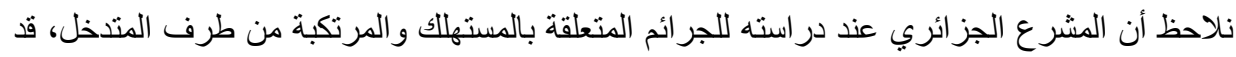

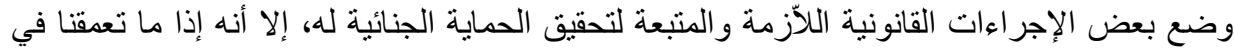

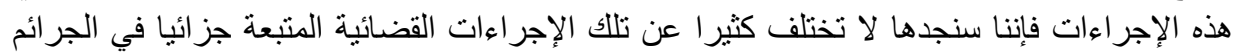

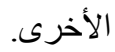

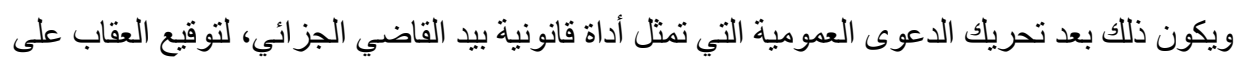

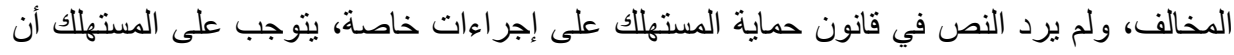

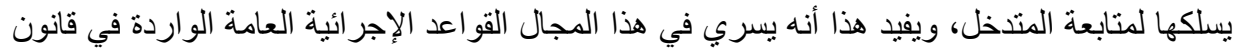

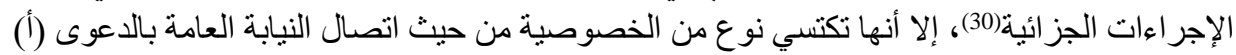
ومن حيث دور التحقيق في إثبات المخالفات (ب).

أ ـ اتصال وكيل الجمهورية بالدعوى العمومية:تعتبر النيابة العامة ممثلة في السيد وكيل

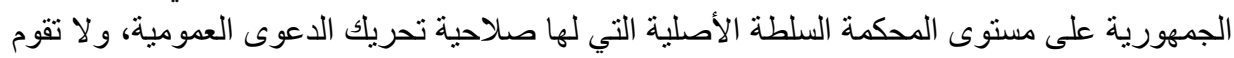

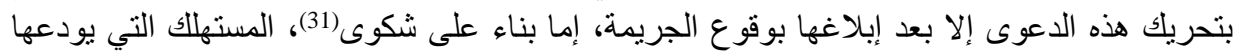

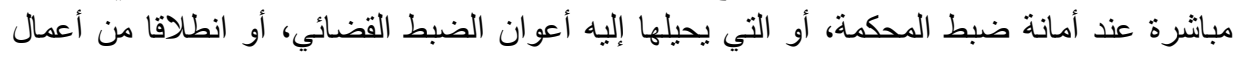

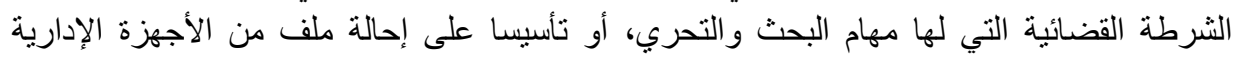

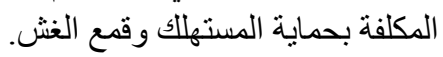

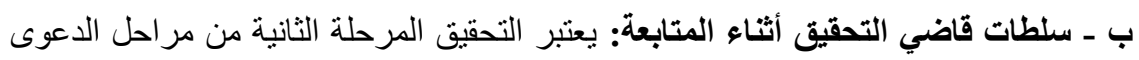

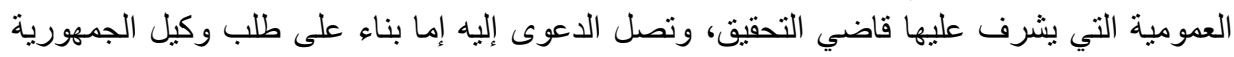

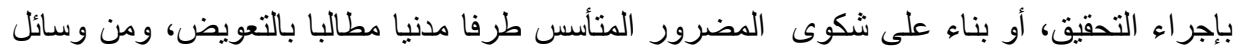

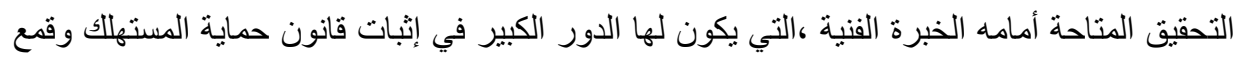

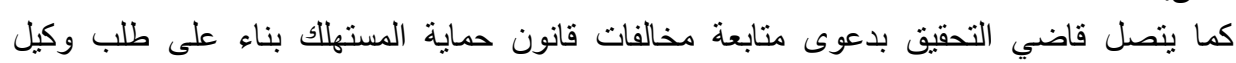

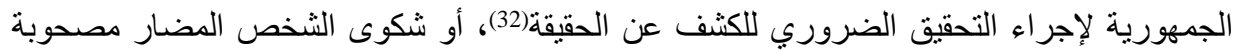

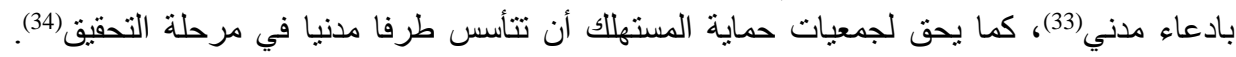

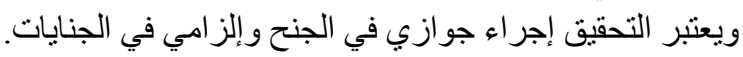

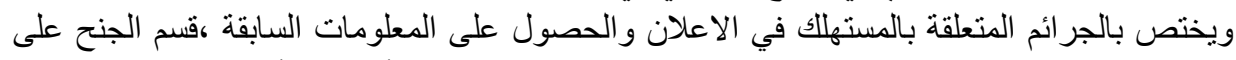

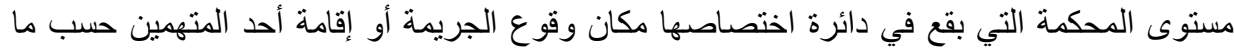

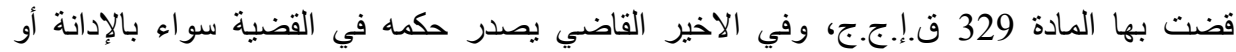

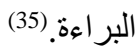

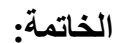

يستخلص مما سلف ذكره أن المشر ع الجز ائري لم يتفطن بعد للإِستخدام السيئ للإشهار و اكتفى بتنبني

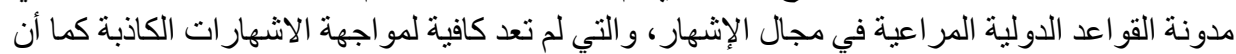
القو اعد العامة الجز ائية تبقى غير كافية لرئر لردعها. 
بالر غم من أن الإشهار التجاري هو مجال حيوي و ضروري سواء بالنسبة للمستهلك كونه يساهم بشكل

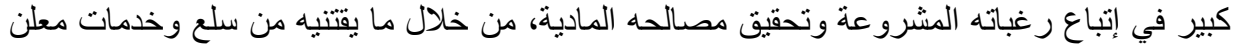

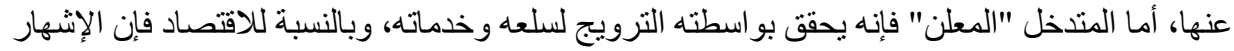

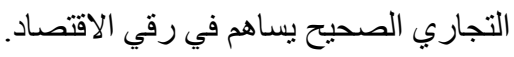

ولكن لن يتحقق كل ذلك في غياب نص قانوني ينظم الإشهار التجاري، إذ المعلن (المتنخل ) بسعى

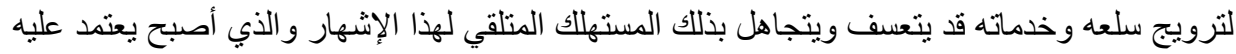

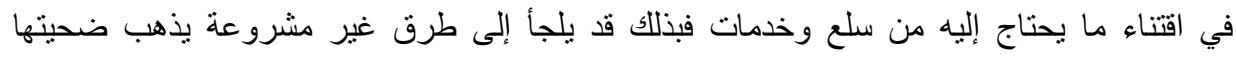
المستهراك.

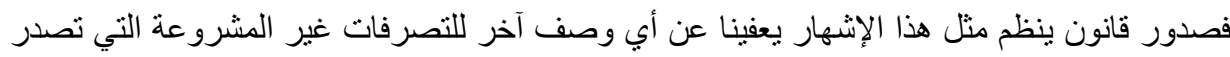

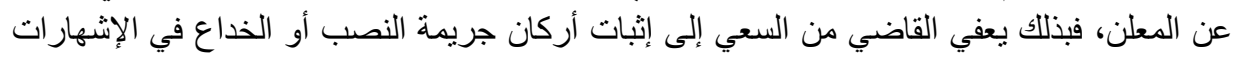

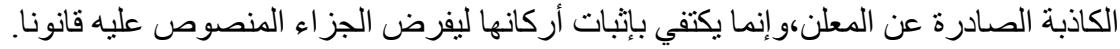

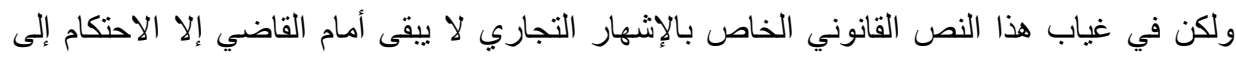

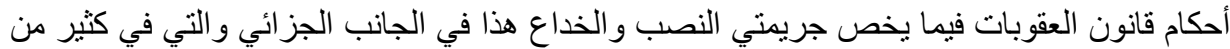

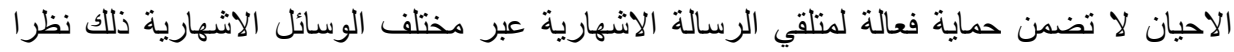

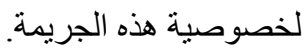

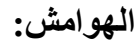

1- الناثف أنطو ان، الإعلانات و العلامات التجارية بين القانون و الإجتهاد ، منشور رات الحلبي الحقوقية.

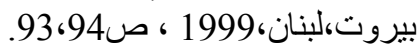
2- الثلقاوي محمد عبد الله ، المسؤولية الجنائية في الإعلان التجاري ،محلية الثرطة ، الإمارات ، بات

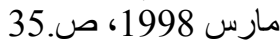
3- قانون رقم 1968-156 المؤرخ في 8 يونيو 1966 يتضمن قانون العقوبات، ج.ر. عدد 49 الصادرة في 1966/10/30

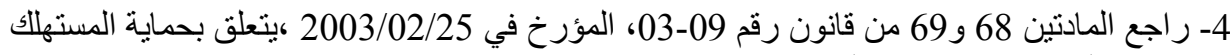

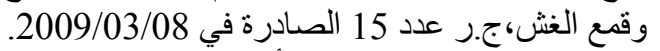

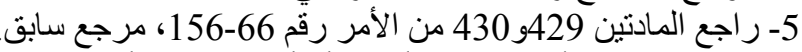

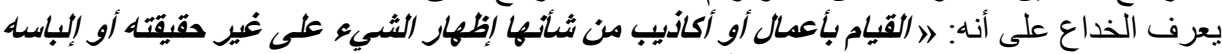

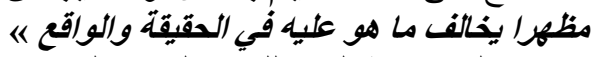

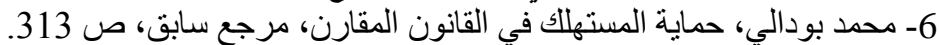

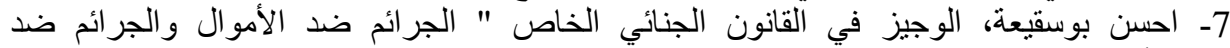

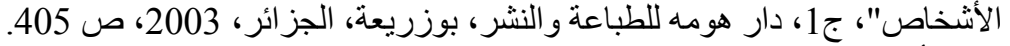

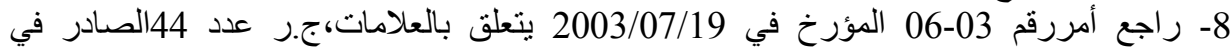
.2003/07/23

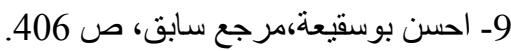

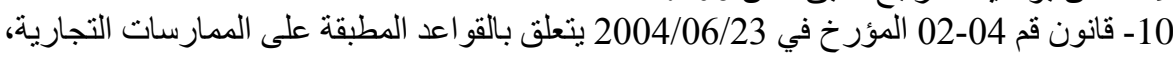
ج.ر. عدد 41 الصادرة في 2004/06/27 المعدل والمتمح بـ فئح 


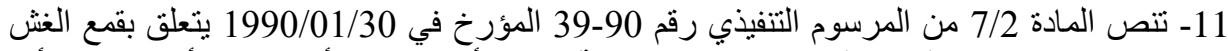

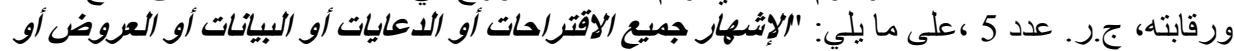

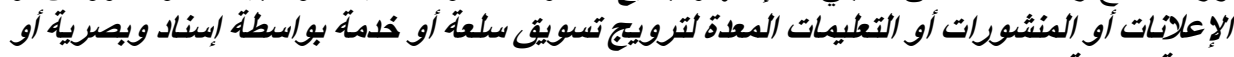

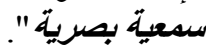

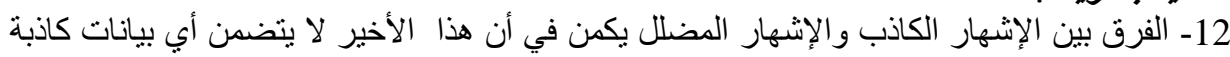

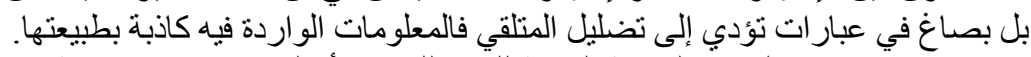

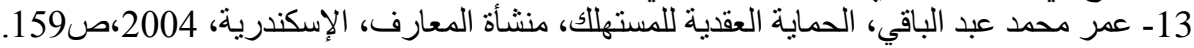

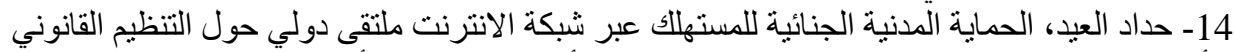

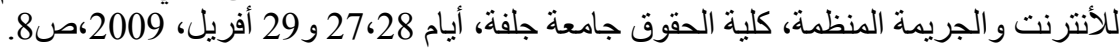

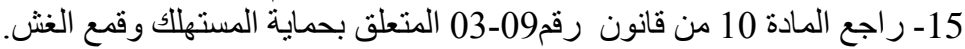

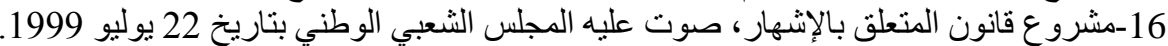

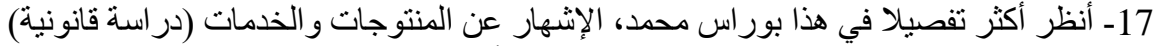
رسالة لنيل شهادة الدكتور اه في القانون الخاص، جامعة أبي بكر بلقايد تلمسان، كلية الحقوق و العلوم العان

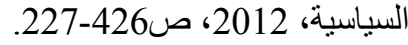

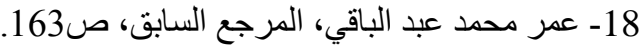
19- أحمد السعيد الزقرد، الحماية المدنية من الدعاية التجارية الكاذبة والدضللة، دار الجامعة الجديدة،

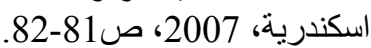
20- عبد الفضيل محمد أحمد، الإعلان على الميلى المنتجات والخدمات من الوجهة القانونية،دار النهضة

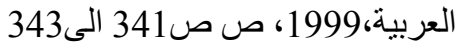
21 - 21 راجع المادة 24 من المشروع. صنع.

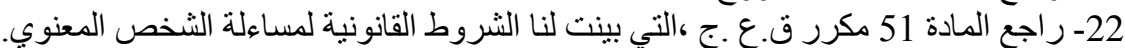

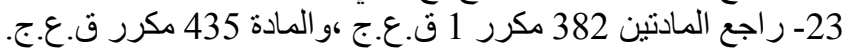

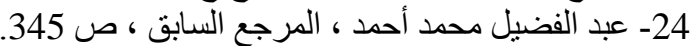
25- الأمر رقم 03- 03 المؤرخ في 2003/07/19 المتعلق بالمنافسة ج.ر عدد 43، المعدل و المتمم .

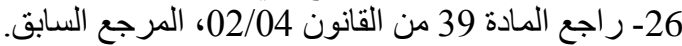

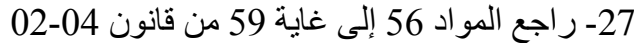

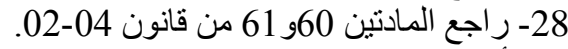

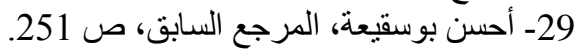

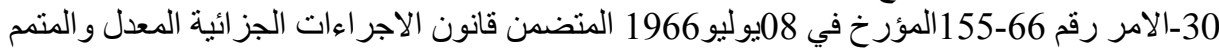

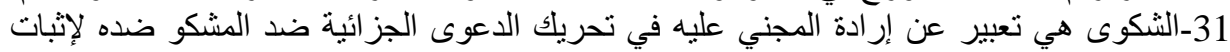
مسؤوليته الجنائية ومعاقبته قانونا.

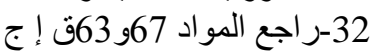

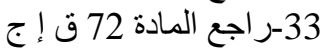

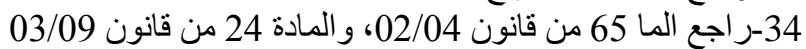
35-راجع المواد 309-310-314-314 ق.إنج 